\title{
Efeito da adição de componentes inorgânicos na resistência mecânica de moldes de areia para fundição
}

\section{(Effect of addition of inorganic components on the mechanical strength of sand molds for casting)}

\author{
M.S. Cilla, M. R. Morelli \\ Departamento de Engenharia de Materiais - DEMa, Universidade Federal de S. Carlos - UFSCar, Rod. \\ Washington Luís, km 235, S. Carlos, SP 13565-905 \\ marceloscilla@ufscar.br,morelli@power.ufscar.br
}

\begin{abstract}
Resumo
O processo de fundição mais rápido, econômico e convencional é o de moldagem em areia a verde, onde o ligante principal é uma argila umedecida (bentonita). Entretanto, devido a exigências tecnológicas, são utilizados também ligantes tóxicos como resinas furânicas, fenólicas ou uretânicas. Novas tecnologias vêm sendo desenvolvidas para a recuperação e inertização das areias, porém as resinas disponíveis atualmente têm como limitação "ecológica" sua origem química. Após sua utilização estes moldes são descartados, e assim, os ligantes tóxicos tornam-se um problema ambiental. Desta maneira, a substituição destes ligantes por compostos orgânicos derivados de fontes renováveis como a resina poliuretana derivada do óleo de mamona minimiza os impactos ambientais, conduzindo o processo de fundição rumo à sustentabilidade, necessária devido ao aumento do rigor da legislação ambiental. Devido ao comportamento térmico do poliuretano vegetal, que se decompõem de maneira mais acentuada quando exposto a altas temperaturas quando comparado aos ligantes orgânicos tradicionais a adição de componentes inorgânicos se faz necessária como promotora da ligação entre os grãos de areia e conseqüente coesão dos moldes durante a etapa de fusão. Neste sentido, o uso de diagramas de fases na previsão do surgimento de fase líquida pela adição de componentes inorgânicos à mistura areia/resina em moldes de areia para fundição e seu efeito na resistência mecânica dos moldes em altas temperaturas, funciona como ferramenta teórica no auxílio à determinação das composições dos moldes de acordo com sua solicitação térmica durante a fusão. Testes iniciais de moldagem e resistência mecânica a temperatura ambiente mostraram que a resina poliuretana derivada da mamona apresenta resultados comparáveis aos das resinas comerciais. Também a adição dos componentes inorgânicos e seu efeito quando submetido a tratamentos térmicos foi comprovada por testes de resistência mecânica a compressão e análise de fotomicrografias das composições estudadas, conforme previsto nos respectivos diagramas de fases.
\end{abstract}

Palavras-chave: fundição, tóxicos, ambiental, inorgânicos, coesão, diagramas de fase.

\begin{abstract}
The casting process faster, economical and conventional is to green sand molding, where the main ligand is a moist clay (bentonite). However, due to technological requirements, are also used as binders toxic furan resin, phenolic or urethane. New technologies have been developed for the recovery and blanketing the sands, but the resins currently available are limited by its chemical origin. After use these molds are discarded, and thus the toxic binders become an environmental problem. Thus, the replacement of these binders by organic compounds derived from renewable sources such as polyurethane resin derived from castor oil minimizes environmental impacts, leading the casting process towards sustainability, necessary because of the increasing stringency of environmental legislation. Because of the thermal behavior of vegetable polyurethane, which decompose in a more pronounced when exposed to high temperatures compared to traditional organic binders the addition of inorganic components is required as a facilitator of the link between the grains sand and consequent cohesion of the molds during stage of fusion. In this sense, the use of phase diagrams to predict the appearance of liquid phase by the addition of inorganic components to the mix sand / resin in sand molds for casting and its effect on mechanical strength at high temperatures of the mold serves as a theoretical tool in helping to determining the composition of the molds according to its thermal stress during melting. Initial tests of molding and mechanical strength at room temperature showed that the polyurethane resin derived from castor oil produces results comparable to those of commercial resins. Also the addition of inorganic components and its effect when subjected to heat treatment is tested for mechanical compression and analysis of photomicrographs of the compositions, as provided in the respective phase diagrams.
\end{abstract}

Keywords: casting, toxic, environmental, inorganic, cohesion, phase diagrams.

\section{INTRODUÇÃO}

O presente trabalho tem como objetivo avaliar o comportamento de componentes inorgânicos em altas temperaturas, quando adicionados em moldes de areia para fundição juntamente com uma resina poliuretano vegetal derivada do óleo de mamona, utilizando como suporte teórico diagramas de fases para a previsão do surgimento de fase 
líquida responsável pela manutenção e aumento da resistência mecânica dos moldes sob ação de altas temperaturas. De maneira prática, medida semelhante já havia sido adotada em 1995, quando a empresa Cadic Corp. [1] e a sua subsidiária CTI Inc., introduziu o processo de Conversão Cadic, que utiliza uma mistura de óxidos de silício e sódio diluídos em álcool para o tratamento de moldes e machos ligados por resinas orgânicas comumente utilizadas. Na prática, moldes e machos após serem produzidos eram mergulhados ou imersos em solução de etanol, secas e, posteriormente, queimados em forno para converter o ligante orgânico a um molde ligado por um sistema inorgânico. Este tratamento pós-produção de ligantes orgânicos resulta na formação de organo-silicatos que posteriormente são convertidos em cerâmica, quando em temperaturas elevadas. Embora este processo goze de algum sucesso, a aceitação tem sido limitada devido à exigência de pós-tratamento dos moldes ligados com sistemas orgânicos com uma solução de etanol de sódio e óxidos de $\mathrm{Si}$, seguido de secagem, queima e, posteriormente, em um forno a $1000{ }^{\circ} \mathrm{C}$. Como vantagem, existe a possibilidade de redução dos níveis de resina orgânica devido ao aumento na resistência final do sistema convertido. Também veios, erosão e outros defeitos podem ser reduzidos, devido às superiores propriedades térmicas das cerâmicas. Outro fator de importância prática deste estudo está na substituição das resinas orgânicas hoje utilizadas por uma resina derivada de fonte renovável, que contribui de maneira eficiente para a redução do problema ambiental relacionando ao descarte das areias de fundição. [2]

Para este trabalho foi adotado outro caminho para a formação de fase cerâmica em altas temperaturas, sem necessidade das etapas de secagem e queima dos moldes.

Como ferramenta teórica, a interpretação dos diagramas de fases relacionados a cada composição estudada forneceu subsídios para a melhor escolha das composições, de acordo com a liga a ser fundida e com base na temperatura de fusão e pressão metalostática. Os diagramas de equilíbrio, ou diagramas de fases são gráficos que mostram as fases presentes num material em equilíbrio com o seu ambiente. Corretamente interpretado, um diagrama de equilíbrio indica o número de fases presentes, suas composições e a percentagem de cada fase, em função da temperatura, da pressão e da composição global do material. Embora a maioria dos materiais de engenharia exista em condição metastável, isto é, fora de equilíbrio, qualquer modificação espontânea se dará em direção ao equilíbrio e muitas informações úteis sobre mudanças de fase em tais materiais podem ser deduzidas a partir dos diagramas de equilíbrio adequados. Os diagramas de equilíbrio são classificados em unários (de um componente), binários e de ordem superior (ternários, quaternários etc.), dependendo do número de componentes puros presentes. Pode-se entender como fase de um material, regiões em escala micro ou até mesmo nanométricas que apresentam composições químicas e/ ou arranjos atômicas específicos. Com freqüência as fases podem possuir a mesma composição química, mas arranjos atômicos diferentes. Para a descrição da estrutura de um material, podem-se usar diagramas que mostram quais são as fases presentes e suas quantidades relativas, em função da temperatura, da pressão e da composição global. A utilização dos diagramas de equilíbrio no estudo dos materiais e processos cerâmicos tem se mostrado cada vez mais indispensável e isto não significa necessariamente que se tenha que admitir a priori que o sistema em questão esteja num estado de equilíbrio. [3]

A partir da análise de fotomicrografias obtidas por microscopia eletrônica de varredura das composições estudadas foi possível visualizar a ação dos componentes inorgânicos como formadores de fase líquida nos moldes de areia submetidos a tratamentos térmicos.

\section{MATERIAIS E MÉTODOS}

Para obtenção de corpos de prova e confecções dos moldes foram utilizados os seguintes componentes: areia industrial de granulometria 60/70 mesh fornecida pela Mineração Jundu; resina poliuretano vegetal (PUV) bicomponente formulada pela mistura a frio de um prépolímero (componente A) e um poliol (componente B), pela empresa Imperveg Com. Prest. Serv. Ltda; diferentes materiais inorgânicos tais como argilito e argila caulinítica pela empresa Minasolo S.A., bentonita sódica natural Argel 27 pela empresa Bentonita União Nordeste Ind. e Com. Ltda., pó de vidro de granulometria 100 mesh (PV \#100) pela da empresa Ematec, filito PDG e filito branco fundente (FB), ambos pela empresa Mineração Itapeva, ulexita anidra e ácido bórico, ambos pela empresa Boro do Sul Ltda. e cal hidratada comercial. Diversas composições foram elaboradas visando à caracterização dos moldes. Ênfase foi dada à determinação da resistência à compressão após tratamento térmico, para verificar a influência da adição de diferentes componentes inorgânicos.

O desenvolvimento experimental utilizado para a determinação das resistências à compressão após tratamento térmico pode ser mais bem descrito separadamente.

\section{Resistência mecânica à compressão após tratamento térmico}

Antes do ensaio para a determinação da resistência mecânica à compressão após tratamento térmico, foram realizadas fusões em moldes preparados de diferentes composições. A seqüência de incorporação do material inorgânico e resina à areia foram realizadas da seguinte maneira: adição e mistura do componente inorgânico em teores entre 1,0 e 5,0\% até completa homogeneização; adição e mistura do componente $\mathrm{B}$ à mistura até completa homogeneização; adição e mistura do componente A à mistura até completa homogeneização. Após a moldagem e etapa de cura, foram realizadas fusões com dois tipos de metais que possuem diferentes temperaturas de fusão e pressões metalostáticas: ferro fundido GGG 40 e liga de alumínio 356.0, com temperaturas de fusão da ordem de 1500 e $700{ }^{\circ} \mathrm{C}$ respectivamente. Em seguida, adotou-se como critério de escolha preliminar, a observação visual das 
peças fundidas (acabamento superficial) e comportamento dos moldes (coesão e colapsibilidade). Desta forma, foram selecionadas três composições $(\mathrm{C} 1$ a $\mathrm{C} 3)$ utilizadas para fusão do ferro fundido e duas (C4 e C5) para a liga de alumínio. As composições escolhidas são mostradas a seguir: composição 1: $98,0 \%$ areia+1\% $\mathrm{CaO}+1 \% \mathrm{H}_{3} \mathrm{BO}_{3}$ (C1); composição 2: 95,0\% areia+5\% FB (C2); composição 3: 95,0\% areia+5\% FPDG (C3); composição 4: 98,5\% areia+1,5\% $\mathrm{H}_{3} \mathrm{BO}_{3}(\mathrm{C} 4)$;composição 5: 95,0\% areia $+5,0 \%$ PV \#100 (C5). Considerando que somente uma parcela do molde sofre ação da temperatura quando do vazamento do metal líquido (parede em contato com o metal), e a adição dos materiais inorgânicos é mínima se comparada à massa de areia utilizada para confecção dos moldes, tomou-se como plausível considerar apenas a contribuição resultante desta adição na determinação dos teores de óxidos e conseqüente interpretação dos respectivos diagramas de fases.

Para a determinação do teor de óxidos em cada composição foi usada a seguinte metodologia: a partir da análise química fornecida para cada matéria-prima, a somatória dos teores de cada óxido foi aproximada para $100 \%$; novamente a somatória dos teores de cada óxido foi reaproximada para $100 \%$ tomando-se somente os óxidos de interesse (majoritários).

$\mathrm{O}$ efeito fundente de cada um dos óxidos alcalinos $\left(\mathrm{K}_{2} \mathrm{O}\right.$ e $\left.\mathrm{Na}_{2} \mathrm{O}\right)$ é muito semelhante e, como o $\mathrm{K}_{2} \mathrm{O}$ favorece a formação de fase líquida a temperaturas mais baixas, é costume discutir aquele efeito em termos do diagrama de equilíbrio de fases do sistema $\mathrm{Al}_{2} \mathrm{O}_{3}-\mathrm{SiO}_{2}-\mathrm{K}_{2} \mathrm{O}$ utilizando o teor conjunto $\left(\mathrm{K}_{2} \mathrm{O}+\mathrm{Na}_{2} \mathrm{O}\right)$. Quanto aos óxidos alcalinoterrosos $(\mathrm{CaO}+\mathrm{MgO})$, eles só estão presentes em teor apreciável no PV\#100. Desta forma, a sua contribuição para o efeito fundente global será considerada apenas nesta última composição (C5). Ou seja, o efeito dos fundentes sobre o sistema $\mathrm{Al}_{2} \mathrm{O}_{3}-\mathrm{SiO}_{2}$, poderá ser discutido em termos dos teores conjuntos de $\left(\mathrm{K}_{2} \mathrm{O}+\mathrm{Na}_{2} \mathrm{O}\right)$ para as composições $\mathrm{C} 2 \mathrm{e}$ $\mathrm{C} 3$, com adições respectivamente de FB e FPDG e dos teores conjuntos de $(\mathrm{CaO}+\mathrm{MgO})$ e $\left(\mathrm{K}_{2} \mathrm{O}+\mathrm{Na}_{2} \mathrm{O}\right)$ na composição C5, com adição de PV\#100.

Para simular o efeito da temperatura na formação de fase líquida a partir dos componentes inorgânicos, usados como promotores da coesão dos grãos de areia foram realizados tratamentos térmicos em corpos de prova moldados segundo a NBR10611 [4]. No caso das composições C1, C2 e C3 as temperaturas de teste foram de 1400,1500 e $1600{ }^{\circ} \mathrm{C}$. Foi utilizado um forno de fusão (sistema elevador) Lindberg Blue. Os tratamentos foram realizados da seguinte maneira: os corpos de prova eram colocados no forno já com o patamar na temperatura estabelecida e desejada, onde permaneciam por aproximadamente seis min [5]. Decorrido este tempo, os mesmos eram retirados rapidamente para resfriar até a temperatura ambiente. Posteriormente, todos foram testados para verificação da resistência mecânica a compressão. Para as composições C4 e C5 adotou-se o mesmo critério de preparação de corpos de prova e teste de resistência mecânica; com temperaturas entre 100 e 1200 ${ }^{\circ} \mathrm{C}$ para os tratamentos térmicos realizados em mufla EDG
3000. Para as composições escolhidas, foram preparadas amostras para análise de microestrutura em microscopia eletrônica de varredura de maneira a evidenciar a influência dos componentes inorgânicos no aumento da resistência mecânica após tratamento térmico pelo surgimento de fase líquida.

\section{RESULTADOS E DISCUSSÃO}

\section{Diagramas de fases (determinação do teor de óxidos)}

A Tabela I apresenta as composições selecionadas para a moldagem e posterior fusão de ferro fundido $(\mathrm{C} 1$ a $\mathrm{C} 3)$ e alumínio (C4 e C5), bem como o teor de óxidos (em \%) presentes em cada uma delas:

Tabela I - Teor percentual dos óxidos majoritários presentes nas composições dos moldes de areia pré-selecionados após fusão.

[Table I - Percentage concentration of major oxides present in the compositions of the sand molds pre-selected after fusion.]

\begin{tabular}{cccccc}
\hline & $\mathrm{SiO}_{2}$ & $(\mathrm{CaO}+\mathrm{MgO})$ & $\mathrm{B}_{2} \mathrm{O}_{3}$ & $\mathrm{Al}_{2} \mathrm{O}_{3}$ & $\left(\mathrm{~K}_{2} \mathrm{O}+\mathrm{Na}_{2} \mathrm{O}\right)$ \\
\hline $\mathrm{C} 1$ & & 64 & 36 & & \\
$\mathrm{C} 2$ & 74.92 & & & 17,02 & 4,94 \\
$\mathrm{C} 3$ & 76,49 & & & 14,86 & 8,65 \\
$\mathrm{C} 4$ & 99,16 & & 0,84 & & \\
$\mathrm{C} 5$ & 79,86 & 11,29 & & & 13,97 \\
\hline
\end{tabular}

A partir desses dados, tais composições foram destacadas nos respectivos diagramas de fases e as temperaturas de aparecimento de fase líquida foram marcadas conforme mostrado a seguir para cada composição:

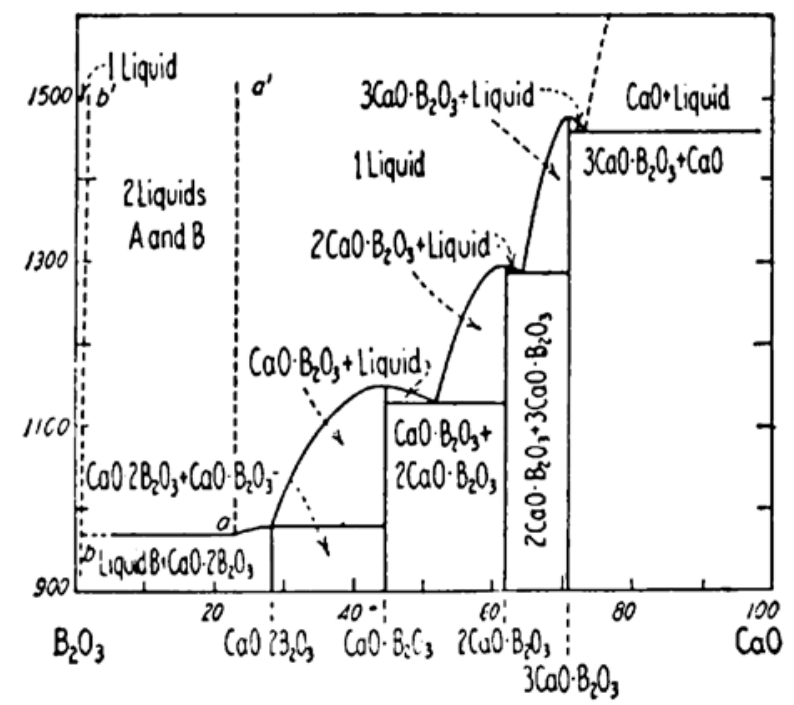

Figura 1: Diagrama de fases de $\mathrm{B}_{2} \mathrm{O}_{3}-\mathrm{CaO}$ com destaque para a linha seccionada que indica o percentual de óxidos presentes na composição $\mathrm{C} 1$.

[Figure 1: Phase diagram of $\mathrm{B}_{2} \mathrm{O}_{3}-\mathrm{CaO}$ with emphasis on the split line that indicates the percentage of oxides in the composition $C 1$. 
Para a composição $\mathrm{C} 1$ (Fig. 1), o teor de óxidos $\mathrm{CaO}$ e $\mathrm{B}_{2} \mathrm{O}_{3}$ presentes no molde é representado pela linha seccionada que mostra o surgimento de líquido resultante da reação eutética em torno de $1280^{\circ} \mathrm{C}$.

Tomando-se o teor de óxidos de acordo com a Tabela I, temos que o ponto em destaque na Fig. 2 representa a localização da composição $\mathrm{C} 2$ em função do percentual de óxidos no diagrama $\mathrm{SiO}_{2}-\mathrm{K}_{2} \mathrm{O}-\mathrm{Al}_{2} \mathrm{O}_{3}$.

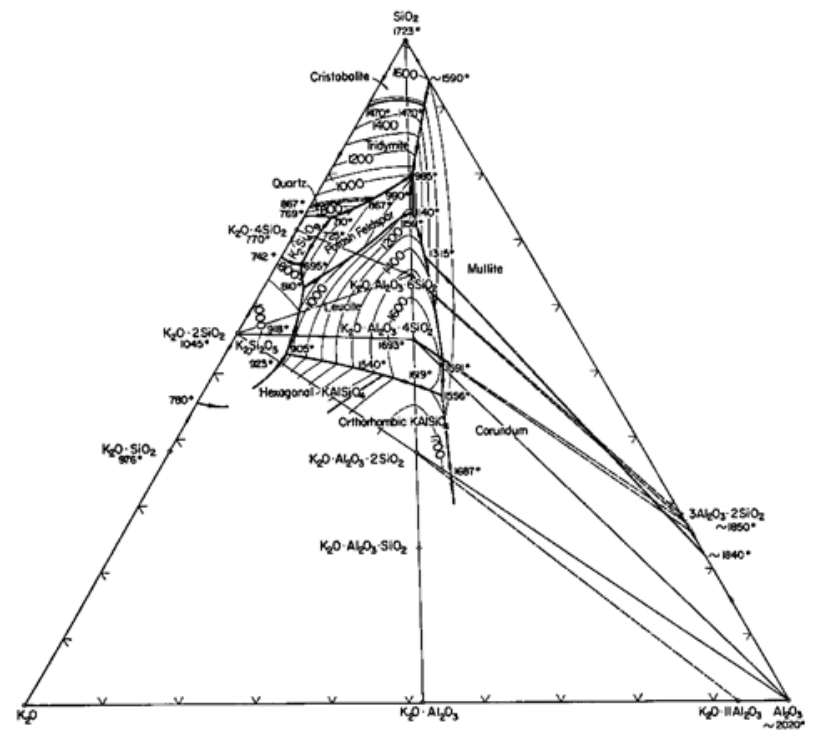

Figura 2: Diagrama de fases de $\mathrm{SiO}_{2}-\mathrm{K}_{2} \mathrm{O}-\mathrm{Al}_{2} \mathrm{O}_{3}$ com destaque referente ao teor presente de óxidos na composição $\mathrm{C} 2$.

[Figure 2: Phase diagram of $\mathrm{SiO}_{2}-\mathrm{K}_{2} \mathrm{O}-\mathrm{Al}_{2} \mathrm{O}_{3}$ especially regarding the content of oxides present in the composition $C 2$.]

Pode-se observar que a composição C2 está localizada no triângulo de compatibilidade sílica $\left(\mathrm{SiO}_{2}\right)$ - mulita $\left(3 \mathrm{Al}_{2} \mathrm{O}_{3} \cdot 2 \mathrm{SiO}_{2}\right)$ - leucita $\left(\mathrm{K}_{2} \mathrm{O} \cdot \mathrm{Al}_{2} \mathrm{O}_{3} \cdot 4 \mathrm{SiO}_{2}\right)$. Neste caso, a

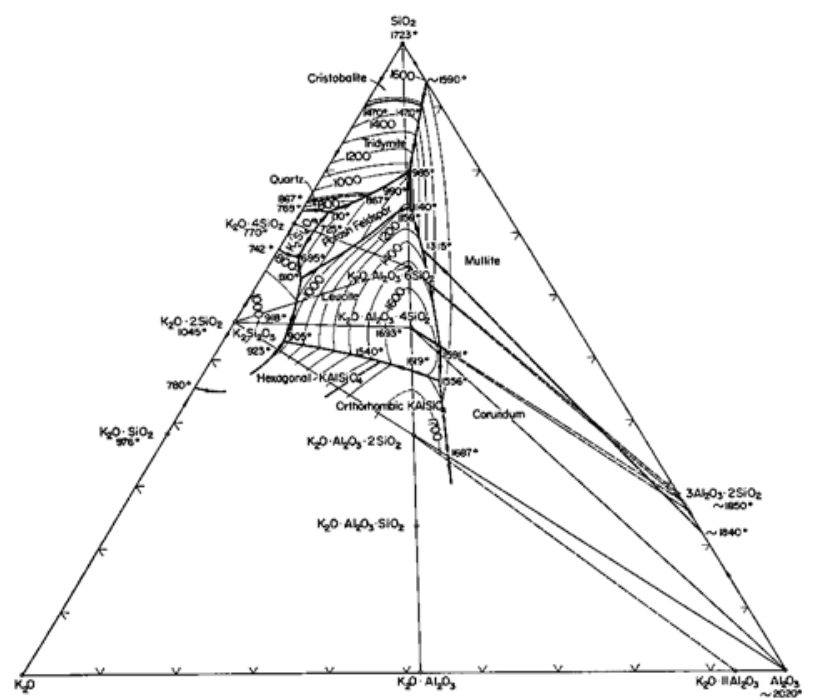

Figura 3: Diagrama de fases de $\mathrm{SiO}_{2}-\mathrm{K}_{2} \mathrm{O}-\mathrm{Al}_{2} \mathrm{O}_{3}$ com referência ao teor de óxidos presentes na composição $\mathrm{C} 3$.

[Figure 3: Phase diagram of $\mathrm{SiO}_{2}-\mathrm{K}_{2} \mathrm{O}-\mathrm{Al}_{2} \mathrm{O}_{3}$ especially regarding the content of oxides present in the composition C3.] temperatura de surgimento do primeiro líquido está em torno de $1140{ }^{\circ} \mathrm{C}$. Como na determinação dos teores de óxidos presentes não foi considerada a presença de impurezas, esta temperatura efetivamente deve ser abaixada em uma condição real. Da mesma maneira que a composição $\mathrm{C} 2$, temos a composição $\mathrm{C} 3$ no diagrama $\mathrm{SiO}_{2}-\mathrm{K}_{2} \mathrm{O}-\mathrm{Al}_{2} \mathrm{O}_{3}$ (Fig. 3), também localizada no triângulo de compatibilidade sílica $\left(\mathrm{SiO}_{2}\right)-$ mulita $\left(3 \mathrm{Al}_{2} \mathrm{O}_{3} \cdot 2 \mathrm{SiO}_{2}\right)$ - leucita $\left(\mathrm{K}_{2} \mathrm{O} \cdot \mathrm{Al}_{2} \mathrm{O}_{3} \cdot 4 \mathrm{SiO}_{2}\right)$.

Tem-se neste caso uma condição muito próxima a anterior, porém devido a um maior teor de óxidos $\left(\mathrm{K}_{2} \mathrm{O}+\mathrm{Na}_{2} \mathrm{O}\right) \mathrm{o}$ surgimento do primeiro líquido ocorre a uma temperatura

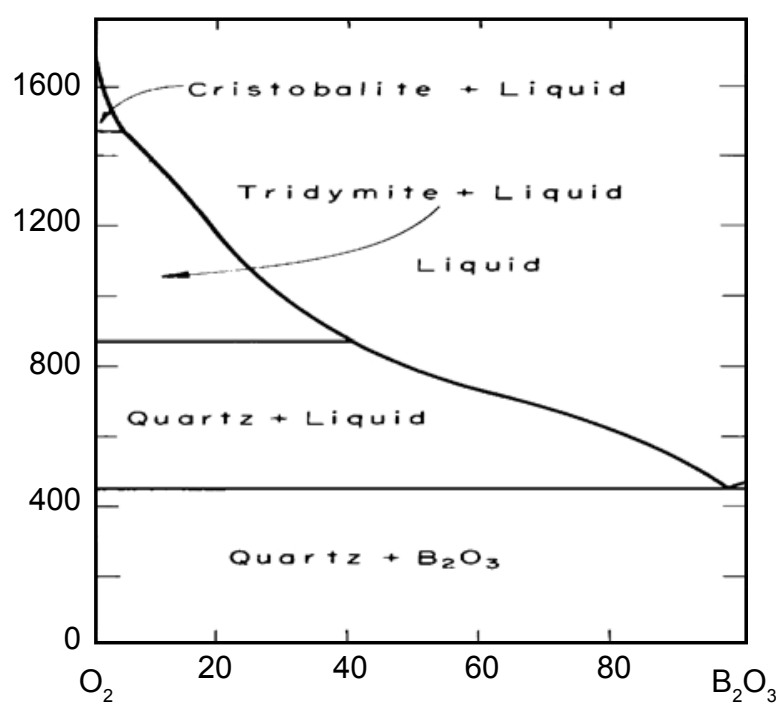

Figura 4: Diagrama de fases de $\mathrm{SiO}_{2}-\mathrm{B}_{2} \mathrm{O}_{3}$ onde a linha tracejada indica o teor de óxidos presentes na composição $\mathrm{C} 4$.

[Figure 4: Phase diagram of $\mathrm{SiO}_{2}-\mathrm{B}_{2} \mathrm{O}_{3}$ where the dashed line indicates the level of oxides present in the composition C4.]

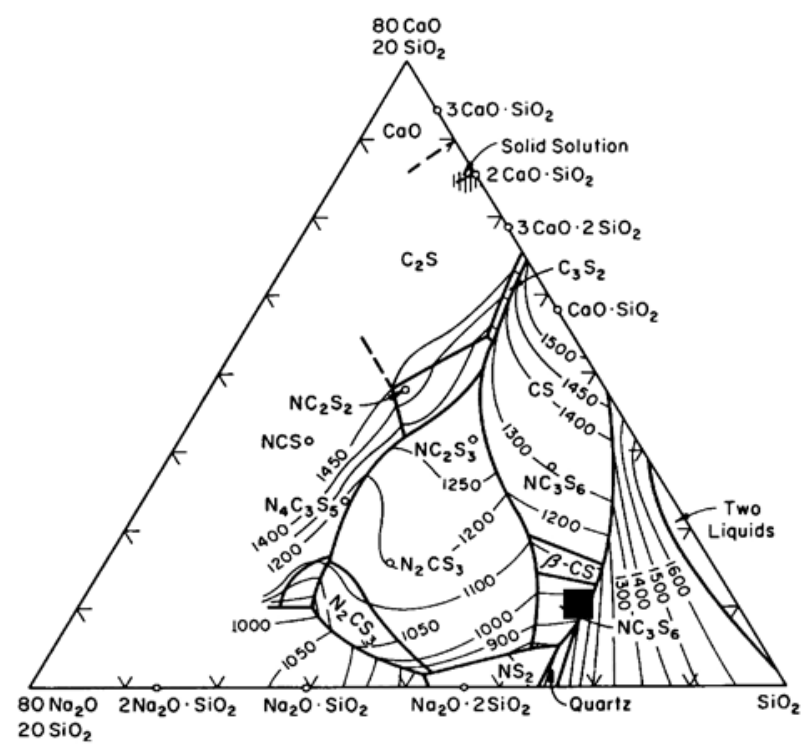

Figura 5: Diagrama de fases de $\mathrm{Na}_{2} \mathrm{O}-\mathrm{SiO}_{2}-\mathrm{CaO}$ com destaque para o teor de óxidos presentes na composição C5 [65].

[Figure 5: Phase diagram of $\mathrm{Na}_{2} \mathrm{O}-\mathrm{SiO}_{2}-\mathrm{CaO}$ especially regarding the content of oxides present in the composition C5.] 
inferior se comparado à composição $\mathrm{C} 2$. Observando-se a composição C4 na Fig. 4, podemos verificar que, seja pelo ponto de fusão do óxido de boro, seja pelo aparecimento de uma reação eutética com o $\mathrm{SiO}_{2}$, ocorre à geração de líquido em temperaturas próximas a $450{ }^{\circ} \mathrm{C}$.

Em relação à composição C5 (Fig. 5), observa-se que a temperatura de aparecimento de líquido está em torno de $1000{ }^{\circ} \mathrm{C}$, que na prática é abaixada pela presença de impurezas que não foram consideradas quando do cálculo do teor de óxidos presentes na matéria-prima.

\section{Resistência mecânica à compressão após tratamento térmico}

As Figs. 6 e 7 mostram o comportamento da resistência mecânica à compressão em função da exposição do

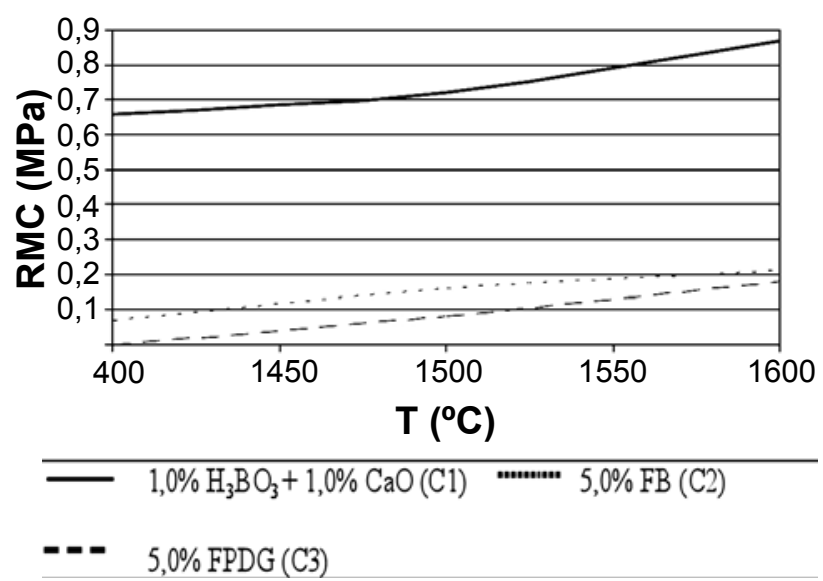

Figura 6: Variação da resistência mecânica à compressão dos corpos de prova em função da temperatura de tratamento térmico para as composições $\mathrm{C} 1, \mathrm{C} 2$ e C3.

[Figure 6: Variation of the mechanical strength of the specimens as a function of heating treatment temperature for compositions C1, C2 and C3.]

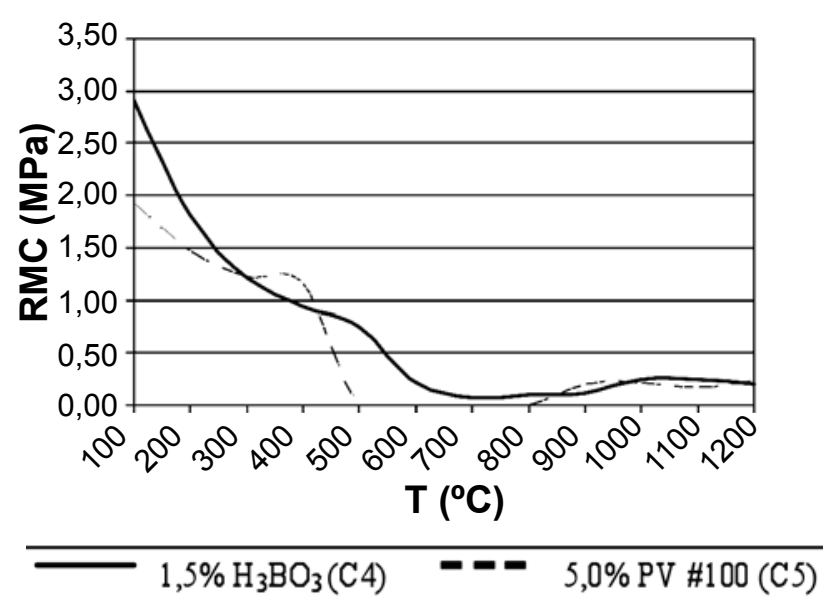

Figura 7: Variação da resistência mecânica à compressão dos corpos de prova em função da temperatura de tratamento térmico para as composições $\mathrm{C} 4$ e $\mathrm{C} 5$.

[Figure 7: Variation of the mechanical strength of the specimens as a function of heating treatment temperature for compositions C4 and C5.] corpo de prova em diferentes temperaturas. Neste caso é possível observar como a fase inorgânica contribuiu para a manutenção ou aumento da resistência pela formação de uma rede entre os grãos de areia resultante do surgimento de fase líquida promovida pelas altas temperaturas. $\mathrm{O}$ surgimento de fase líquida em altas temperaturas pode ser predito a partir dos diagramas de fase, porém devido à pequena adição de óxidos em relação à areia e à condição de "não-equilíbrio" promovida pelo aquecimento repentino da parede do molde, quando da etapa de fusão, a influência da fase líquida como promotora da coesão entre os grãos de areia só pode ser observada em temperaturas superiores às de aparecimento do primeiro líquido, quando existe uma quantidade de fase líquida suficiente para formar "pontes" entre os grãos de areia.

Análise da microestrutura dos moldes por microscopia eletrônica de varredura

De acordo com as fotomicrografias da composição C4 (Fig. 8), que melhor ilustram a formação de fase líquida após tratamento térmico, se pode observar como a adição
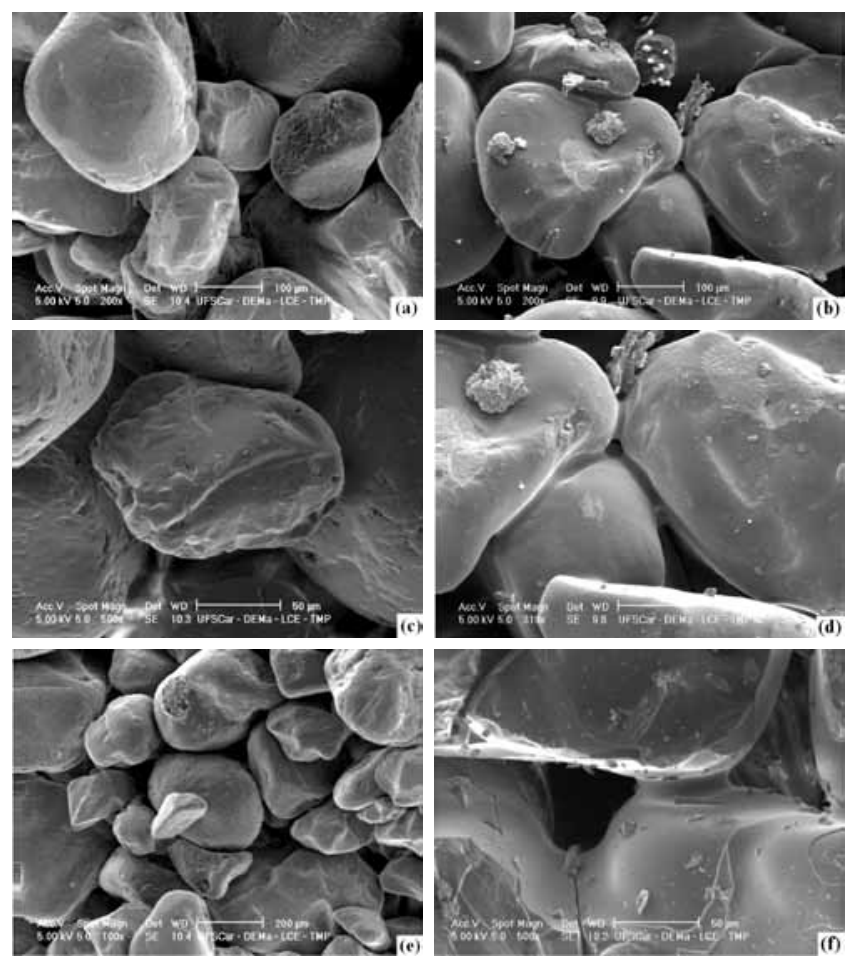

Figura 8: Micrografias obtidas pormicroscopia eletrônica de varredura referentes à composição C4 ilustrando o efeito da temperatura sobre os componentes inorgânicos e conseqüente formação de fase líquida após tratamento térmico. a) sem tratamento térmico, b) tratamento térmico a $900{ }^{\circ} \mathrm{C}, \mathrm{c}$ ) sem tratamento térmico, d) tratamento térmico a $\left.900{ }^{\circ} \mathrm{C}, \mathrm{e}\right)$ sem tratamento térmico, f) tratamento térmico a $1600{ }^{\circ} \mathrm{C}$. [Figure 8: SEM micrographs of composition C4 illustrating the effect of temperature on the inorganic components and consequent formation of liquid phase after heat treatment. a) without heat treatment, $b$ ) heat treatment at $900{ }^{\circ} \mathrm{C}, c$ ) no heat treatment, d) heat treatment at $900{ }^{\circ} \mathrm{C}$, e) without heat treatment, f) heat treatment at $\left.1600{ }^{\circ} \mathrm{C}.\right]$ 
de componentes inorgânicos, neste caso o ácido bórico, atua como um ligante dos grãos de areia em altas temperaturas.

\section{CONCLUSÕES}

A resistência mecânica após tratamento térmico aumenta quando a temperatura de queima aumenta até temperaturas próximas às de fusão de ferrosos (em torno de $1500{ }^{\circ} \mathrm{C}$ ), para composições que contém filito como formador de fase líquida (C2 e C3). A composição constituída pela mistura de ácido bórico e óxido de cálcio (C1) apresentou um melhor desempenho nas mesmas condições de ensaio, com uma resistência mecânica superior às demais em todas as temperaturas de ensaio. Já para as composições C4 e C5 o comportamento da resistência mecânica entre 900 e $1200{ }^{\circ} \mathrm{C}$ é semelhante, porém a composição $\mathrm{C} 4$ apresenta um comportamento mais estável, inclusive na faixa de temperatura de fusão do alumínio $\left(\sim 700{ }^{\circ} \mathrm{C}\right)$ e com menor redução da resistência em temperaturas inferiores. Sendo assim, torna-se mais eficiente para fusão de metais não ferrosos como alumínio, bronze e latão. Conforme previsto nos diagramas e evidenciado nas fotomicrografias, um aumento na temperatura de exposição do corpo de prova contribui de maneira a aumentar a quantidade de fase líquida.

\section{AGRADECIMENTOS}

Ao $\mathrm{CNPq}$ pelo apoio financeiro para a realização deste estudo e ao Prof. Claudemiro Bolfarini por ceder as instalações do laboratório de fundição do DEMa (UFSCar) para a realização dos testes de fusão.

\section{REFERÊNCIAS}

[1] N. Sasaki, Foundry Management \& Technology, disponível em http://www.foundrymag.com/zone/ sandbinders/news/83914/a_revolutionary_inorganic_core_ and_mold_making_process. Consulta em 10/08/2009.

[2] M. S. Cilla, M. R. Morelli, Anais XIX CBECIMAT, Campos do Jordão, SP (2010) 3260.

[3] A. M. Segadães, Diagramas de fases. Teoria e aplicação em cerâmica, Edgard Blücher, S. Paulo, SP (1987) preâmbulo.

[4] Associação Brasileira de Normas Técnicas, Cavidade das caixas-de-macho para confecção de corpos-de-prova para ensaios tecnológicos em laboratórios de areias Dimensões, NBR 10611, RJ (1989).

[5] G. Y. Gerasimov, Y. M. Pogosbekyan, J. Eng. Thermophys. 80, 3 (2007) 545-553.

(Rec.02/02/2011, Ac. 27/04/2011) 